\title{
Utilization Pattern of Oral Hypoglycemic Agents for Diabetes Mellitus Type 2 Patients Attending Out-Patient Department at a University Hospital in New Delhi
}

\author{
Mohammad Shamshir Alam 1,2*, Mohammed Aqil1', Syed Akmal Shah Qadry33, Prem Kapur4, \\ Krishna K. Pillai ${ }^{1}$ \\ ${ }^{1}$ Faculty of Pharmacy, Hamdard University, New Delhi, India \\ ${ }^{2}$ Deparment of Clinical Pharmacy, Unaizah College of Pharmacy, Qassim University, Buraydah, KSA \\ ${ }^{3}$ IIMT College of Pharmacy, Greater Noida, India \\ ${ }^{4}$ Hamdard Institute of Medical Sciences \& Research and Hakeem Abdul Hameed Centenary Hospital, Hamdard \\ University, New Delhi, India \\ Email: shamshir pharma@yahoo.com
}

Received 26 April 2014; revised 27 May 2014; accepted 8 June 2014

Copyright (C) 2014 by authors and Scientific Research Publishing Inc.

This work is licensed under the Creative Commons Attribution International License (CC BY).

http://creativecommons.org/licenses/by/4.0/

(c) ()

\begin{abstract}
Diabetes mellitus is the chronic disorder emerging as a major world health problem which increases the rate of morbidity and mortality. The aim of the present study was to ascertain patterns of prescription of oral hypoglycemic agents to type 2 diabetic patients attending a university hospital, and to assess patient compliance. A prospective, observational and non-comparative study was conducted in $\mathbf{2 0 0}$ established diabetes mellitus type 2 patients attending outpatient department at Majeedia Hospital, New Delhi, India. Prescriptions from registered patients were included in the study. Once the consultation by the physician was over, the prescriptions were reviewed and the patients were interviewed. The information was collected in an inhouse designed documentation proforma. In a pool of 200 type 2 diabetics, more than half were female $(n=106,53 \%)$. The mean age of the patients were found to be $50.4 \pm 11.7$ years and mean body mass index, $25.8 \pm$ $4.4 \mathrm{~kg} / \mathrm{m}^{2}$. A total of 432 oral hypoglycemic agents were prescribed to the patients. Highly significant number of patients was prescribed combination therapy, $(n=143,71.5 \%)$ as compared to monotherapy $(n=57,28.5 \%)$, p-value $<0.0001$. Biguanides were the most commonly prescribed class of oral hypoglycemic agents, followed by sulphonylureas, thiazolidinediones and alpha-glucosidase inhibitors. Good compliance was seen in only $\mathbf{7 7 . 5 \%}$ of the patients. Metformin was found to be the most commonly prescribed medicine.
\end{abstract}

\footnotetext{
*Corresponding author.
}

How to cite this paper: Alam, M.S., Aqil, M., Qadry, S.A.S., Kapur, P. and Pillai, K.K. (2014) Utilization Pattern of Oral Hypoglycemic Agents for Diabetes Mellitus Type 2 Patients Attending Out-Patient Department at a University Hospital in New Delhi. Pharmacology \& Pharmacy, 5, 636-645. http://dx.doi.org/10.4236/pp.2014.57073 


\section{Keywords}

\section{Drug Utilization, Medicine Usage Evaluation, Oral Hypoglycemic Agent, Diabetes Mellitus Type 2, Prescribing Pattern}

\section{Introduction}

Diabetes mellitus (DM) is one of the oldest diseases known to man, which was the first reported in Egyptian literature about 3000 years ago [1]. The name diabetes was first given by the Greek Physician Aretaeus (30 90CE). Avicenna, is the famous Arabian physician who first described the complications and progression of the disease [2]. People living with type 2 DM are more vulnerable to various forms of both short and long-term complications, which often lead to their premature death.

In 1889, Joseph von Mering and Oskar Minkowski discovered the role of pancreas in diabetes. Sir Edward Albert Sharpey-Schafer in 1910 found that diabetes resulted from lack of insulin. Bantin, Best and Collip purified the hormone insulin from pancreas of cows at the University of Toronto. This led to the availability of an effective treatment for diabetes in 1922. Trials to prepare an orally administrated antidiabetic agent ended successfully after first marketing of tolbutamide and carbutamide in 1955.

Diabetes mellitus type 2 is a chronic disease characterized by coexisting insulin deficiency and insulin resistance, with the resultant hyperglycemia leading to micro and macro vascular complications [3]-[6]. Complications include altered metabolism of lipids, carbohydrates, protein and an increased risk of vascular disease complication [7] [8]. The diagnosis is based on the American Diabetic Association (ADA) guidelines of 1997 or World Health Organization (WHO) national diabetic group criteria of 2006, which is for a single raised glucose reading with symptoms (polyuria, polydipsia, polyphagia and weight loss), or raised values on two occasions [9] [10] (Table 1).

Type 2 diabetes is much more common and accounts for around $90 \%$ of all diabetes cases worldwide. It occurs most frequently in adults but is being observed increasingly in adolescents as well [8] [11]. WHO has estimated that, in 2000, 31.7 million individuals were affected by diabetes in India and these figures are expected to rise to 79.4 million by the year 2030 [12]. A recent survey depicts that $4 \%$ of the adults in India suffered from diabetes in the year 2000 and it is expected to increase to $6 \%$ by the year 2025 [13]. Indeed, India today leads the world with largest number of diabetic subjects in any given country [14] [15]. Type 2 diabetes affects over 7\% of the general US population at an annual cost of $\$ 132$ billion [16].

Because of the progressive nature of the disease, an evolving treatment strategy is therefore necessary to maintain both fasting and postprandial glycemic control. ADA and European Association for the Study of Diabetes (EASD) Consensus recommended a target of $\mathrm{HbA1c}<7 \%$ for good glucose control in clinical practice [17]. Insulin therapies are required when dietary restrictions and lifestyle modifications combined with oral hypoglycemic agents (OHAs) fails to provide acceptable metabolic control [18]. United Kingdom Prospective Diabetes Study (UKPDS) advocates for increasing requirement of multiple therapies in patients with type 2 diabetes to achieve blood glucose (BG) target control [19].

Diabetes mellitus requires ongoing medical care as well as patient and family education both to prevent acute illness and to reduce the risk of long term complications. Evaluation of drug use has become an integral part of the pharmacotherapy. Participation in drug utilization study programmes can directly improve the quality of

Table 1. Test indicated for diagnosis of diabetes mellitus type 2.

\begin{tabular}{cccl}
\hline S. No. & Name of test & Normal value & Disease condition \\
\hline 1. & Glycated hemoglobin HbA1c & Below 5.7 percent & $\begin{array}{l}\text { An HbA1c level of } 6.5 \text { percent or higher on } \\
\text { two separate tests indicates diabetes }\end{array}$ \\
2. & Fasting blood sugar & $\begin{array}{l}\text { A fasting blood sugar level less } \\
\text { than } 100 \mathrm{mg} / \mathrm{dL}(5.6 \mathrm{mmol} / \mathrm{L})\end{array}$ & $\begin{array}{l}\geq 7.0 \mathrm{mmol} / \mathrm{L}(126 \mathrm{mg} / \mathrm{dL}) \text { on two separate } \\
\text { tests indicates diabetes }\end{array}$ \\
3. & Oral glucose tolerance test & $\begin{array}{l}\text { A blood sugar level less than } \\
140 \mathrm{mg} / \mathrm{dL}(7.8 \mathrm{mmol} / \mathrm{L})\end{array}$ & $\begin{array}{l}\geq 11.1 \mathrm{mmol} / \mathrm{L}(200 \mathrm{mg} / \mathrm{dL}) \mathrm{plasma} \text { glucose level } \\
\text { of an oral glucose after two hours indicates diabetes. }\end{array}$ \\
\hline
\end{tabular}


patients' care, by preventing the use of unnecessary or irrational drug therapy and by preventing adverse drug reactions [20]. Drug utilization studies provide physicians with feedback on their performance and assist the design of educational programmes that may improve prescribing and drug use performance [21].

Considering the fact that, India carries a huge diabetic population which is swelling further, medicine utilization studies might be one of the strategies to rationalize the medicine use in diabetics and to manage disease better in the community. Hence a medicine utilization study of OHAs was carried out at the Medicine Outpatient Department (OPD) in Majeedia Hospital. There were two aims of the study to describe patterns of prescription of medicines to diabetics attending the hospital, and to assess patient compliance, which will serve as a good reference in analyzing prescribing trends and to formulate guidelines for rational prescribing of diabetic medicines in the hospital.

\section{Materials and Method}

\subsection{Study Design and Study Site}

It was a prospective, observational and non-comparative study conducted at Medicine OPD in Majeedia Hospital, New Delhi, India, which is a 150-bed multi-specialty hospital.

\subsection{Methods}

The present study was carried out in 200 established type 2 diabetes patients, who visited the hospital for treatment during the time period of January 2005 to April 2005. The study protocol was approved by the Jamia Hamdard Institutional Review Board (JHIRB), vide letter number (02/05, dated 13 January 2005). The purpose and other details of the study were discussed with the patients. An oral consent was taken from all the participating patients, prior inclusion in the study. Type 2 diabetes mellitus patients, irrespective of age and sex, who were prescribed at least one OHA were included in the present study. Diagnosed diabetic patients who do not receive pharmacological therapy, unable to reply verbal questions as well as mentally retarded and unconscious patients were excluded from the study.

Once the consultation by the physician was over, the prescriptions were reviewed and the patients were interviewed using structured questionnaire (open question method). On every visit, information regarding the use of medicines was given to the patients. All the participating patients were asked to bring the remaining medicines as well as empty strips with them on next visit. Data were collected by a registered pharmacist that included registered patients only. The information included patients demographic details like age, sex, body weight, height, major disorders, comorbid conditions, family history, number of medicines prescribed, classes of medicines prescribed, medicine brand, secondary failure and compliance with the therapy.

The failure of OHAs to control blood glucose after a period of success is referred to as secondary failure [22]. Because measures of glycemic control were not available of all the patients, a utilization proxy measure of switching or addition of another agent and after discussion with the treating physicians was used to estimate secondary failure.

Although various types of methods are available for assessing patient compliance with the prescribed therapy that includes integration, residual tablet count, urine markers and drug analysis. In integration method, patients are interviewed regarding the use of medicines, so there are chances of incomplete information or wrong information. Other two methods like urine markers and drug analysis are time consuming, expensive and invasive in which unnecessary biological testing is required. Tablet counting, which is easy to apply and low cost, can also be used as standard, although it presents more accuracy problems than electronic monitoring [23]. Residual tablet counting method is more feasible as it is less time consuming, does not require any biological testing, hence in our setting, patients' compliance was determined by residual tablet counting method. Compliance data were documented as either $<80$ or $\geq 80 \%$ intake of recommended dosage regimen with the therapy at each visit. This limit (either $<80$ or $\geq 80 \%$ intake of recommended dosage regimen) was originally used to assess compliance to medication in patients with hypertension.

\subsection{Statistical Analysis}

The differences in proportions were compared by unpaired t-test where appropriate. Statistical significance was set for $\mathrm{p}<0.05$. All statistical analysis was performed using GraphPad InStat software Version 3.06. 


\section{Results}

During the study period, a total of 5530 patients with differing medical problems visited Medicine OPD in Majeedia hospital. Out of these 200 (3.6\%) suffering from type 2 diabetes mellitus, were selected for the study. More than half $(n=106,53 \%)$ of the patients were females as compared to males $(n=94,47 \%)$. The mean age of the patients was found to be $50.4 \pm 11.7$ years and mean body mass index (BMI), $25.8 \pm 4.4 \mathrm{~kg} / \mathrm{m}^{2}$, more than the normal value (Table 2). A large number of patients, 65 (32.5\%) were under the age group of 41 - 50 years, followed by 61 (30.5\%) and 39 (19.5\%) in the age range of 51 - 60 and 31 - 40 years, respectively. Familial association with type 2 diabetes was seen in 36 (18\%) of the patients. Male patients ( $\mathrm{n}=20,55.6 \%)$ have shown more family history of diabetes mellitus than female patients $(n=16,44.4 \%)$.

During the study period, a total of 432 OHAs were prescribed to the patients. Insulin was prescribed in 17 patients along with OHAs. The average number of OHAs prescribed per prescription was found to be 2.2. Biguanides $(\mathrm{n}=160,37 \%)$ were the most commonly prescribed class, followed by sulphonylureas $(\mathrm{n}=138,31.9 \%)$, thiazolidinediones $(\mathrm{n}=107,24.8 \%)$ and alpha-glucosidase inhibitors $(\mathrm{n}=27,6.3 \%)$. Among individual medicines, metformin $(n=160,37 \%)$ was the most frequently prescribed OHAs, followed by pioglitazone $(n=85$, 19.7\%), glimepiride $(n=81,18.7 \%)$ and gliclazide $(n=48,11.1 \%)$ (Table 3$)$. A significant number of patients were prescribed combination therapy $(n=143,71.5 \%)$ as compared to monotherapy ( $n=57,28.5 \%), p<0.0001$. Fixed dose combination $(n=251,58.1 \%)$ were more preferred over individual medicine $(n=181,41.9 \%)$ given concurrently, extremely significant $\mathrm{p}<0.0001$. The patients were treated with one $(\mathrm{n}=57,28.5 \%)$, two $(\mathrm{n}=74$, $37 \%)$, three $(n=51,25.5 \%)$, four $(n=16,8 \%)$ and five $(n=2,1 \%)$ OHAs. Drug duplication was observed in five prescriptions (two in 5 drug regimen and three in 4 drug regimen). Almost all the medicines ( $\mathrm{n}=429$, 99.3\%) were prescribed by brand name, only a fraction by generic name $(n=3,0.7 \%)$. Upward dose change was observed in 13 (6.5\%), while change in frequency was seen in 22 (11\%) of the study population.

Table 2. Patient demographics $(n=200)$.

\begin{tabular}{cc}
\hline Study population & 200 type 2 diabetes mellitus \\
\hline Gender & 94 males (47\%) 106 females (53\%) \\
Mean age & $50.4 \pm 11.7$ years \\
Mean BMI & $25.8 \pm 4.4 \mathrm{~kg} / \mathrm{m}^{2} 110(55 \%)$ had BMI $\geq 25 \mathrm{~kg} / \mathrm{m}^{2}$ \\
Family history & $36(18 \%)$ \\
\hline
\end{tabular}

Table 3. Type of oral hypoglycemic agents prescribed.

\begin{tabular}{|c|c|c|c|}
\hline Class & Drugs & Number of patients prescribed & \% Consumption \\
\hline & Glimepiride & 81 & 18.7 \\
\hline & Gliclazide & 48 & 11.1 \\
\hline \multirow[t]{3}{*}{ Sulphonylureas } & Glibenclamide & 3 & 0.7 \\
\hline & Glipizide & 6 & 1.4 \\
\hline & Total & 138 & 31.9 \\
\hline \multirow[t]{2}{*}{ Biguanides } & Metformin & 160 & 37 \\
\hline & Pioglitazones & 85 & 19.7 \\
\hline \multirow[t]{3}{*}{ Thiazolidinediones } & Rosiglitazone & 22 & 5.1 \\
\hline & Total & 107 & 24.8 \\
\hline & Acarbose & 15 & 3.5 \\
\hline \multirow[t]{3}{*}{ Alpha-glucosidase inhibitors } & Miglitol & 12 & 2.8 \\
\hline & Total & 27 & 6.3 \\
\hline & Grand total & 432 & 100 \\
\hline
\end{tabular}


It was observed that only 155 (77.5\%) of the patients showed good compliance ( $\geq 80 \%$ intake of recommended dosage regimen) with the therapy. More compliance was observed in case of female ( $n=86,55.5 \%)$ as compared to male patients $(n=69,44.5 \%)$. Patients were found to be more compliant with biguanides, $(80 \%)$, followed by sulphonylureas (79.7\%), thiazolidinediones (77.6\%) and alpha-glucosidase inhibitors (70.4\%). Maximum compliance was observed with glibenclamide (100\%), followed by miglitol (83.33\%) and glimepiride (82.72\%) (Table 4). Secondary failure was observed in 15 (7.5\%) of the study population. Secondary failure was found to be slightly more in males (53.3\%) as compared to females (46.7\%). Maximum secondary failure was found with glibenclamide (100\%), followed by glipizide (16.7\%), miglitol (16.2\%) and metformin (8.1\%). No secondary failure was observed in case of acarbose (Table 5). A very high percentage (58.5\%) of diabetes patients were found to be comorbid ( $p<0.0001$, extremely significant) with different types of diseases that included hypertension, (31\%), followed by myocardial infarction, ischemic heart disease and hypothyroidism (3.5\% each) (Table 6).

Table 4. Patients compliance with oral hypoglycemic agents.

\begin{tabular}{ccccc}
\hline Class of OHA Prescribed & $\begin{array}{c}\text { Name of OHA } \\
\text { prescribed }\end{array}$ & $\begin{array}{c}\text { Total number of OHA } \\
\text { prescribed }\end{array}$ & $\begin{array}{c}\text { Number of OHA } \\
\text { compliance }\end{array}$ & $\begin{array}{c}\text { \% of OHA } \\
\text { compliance }\end{array}$ \\
\hline \multirow{3}{*}{ Sulphonylurea } & Glimepiride & 81 & 67 & 82.7 \\
& Gliclazide & 48 & 36 & 75 \\
& Glibenclamide & 3 & 3 & 100 \\
Biguanides & Glipizide & 6 & 4 & 76.7 \\
& Total & 138 & 110 & 80 \\
Thiazolidinediones & Metformin & 160 & 128 & 77.6 \\
& Pioglitazone & 85 & 66 & 77.3 \\
Alpha-glucosidase inhibitors & Rosiglitazone & 22 & 83 & 77.6 \\
& Total & 107 & 9 & 60 \\
\hline
\end{tabular}

Table 5. Secondary failure observed with oral hypoglycemic agents.

\begin{tabular}{|c|c|c|c|c|}
\hline Class of OHA Prescribed & $\begin{array}{l}\text { Name of OHA } \\
\text { prescribed }\end{array}$ & $\begin{array}{c}\text { Total number } \\
\text { of OHA prescribed }\end{array}$ & $\begin{array}{l}\text { Number of drug responsible } \\
\text { for secondary failure }\end{array}$ & $\begin{array}{l}\text { \% secondary } \\
\text { failure }\end{array}$ \\
\hline \multirow{5}{*}{ Sulphonylurea } & Glimepiride & 81 & 6 & 7.4 \\
\hline & Gliclazide & 48 & 2 & 4.2 \\
\hline & Glibenclamide & 3 & 3 & 100 \\
\hline & Glipizide & 6 & 1 & 16.7 \\
\hline & Total & 138 & 12 & 8.7 \\
\hline \multirow[t]{2}{*}{ Biguanides } & Metformin & 160 & 13 & 8.1 \\
\hline & Pioglitazone & 85 & 4 & 4.7 \\
\hline \multirow[t]{3}{*}{ Thiazolidinediones } & Rosiglitazone & 22 & 2 & 9.1 \\
\hline & Total & 107 & 6 & 5.6 \\
\hline & Acarbose & 15 & 0 & 0 \\
\hline \multirow[t]{2}{*}{ Alpha-glucosidase inhibitors } & Miglitol & 12 & 2 & 16.2 \\
\hline & Total & 27 & 2 & 7.4 \\
\hline
\end{tabular}


Table 6. Diabetes patients and associated concomitant diseases.

\begin{tabular}{|c|c|c|}
\hline Diabetes with comorbid conditions & Number of disease cases & $\%$ of the disease cases* \\
\hline Diabetes mellitus + Hypertension & 62 & 31 \\
\hline Diabetes mellitus + Myocardial infarction & 7 & 3.5 \\
\hline Diabetes mellitus + Gout & 2 & 1 \\
\hline Diabetes mellitus + Congestive heart failure & 4 & 2 \\
\hline Diabetes mellitus + Ischemic heart disease & 7 & 3.5 \\
\hline Diabetes mellitus + Asthma & 5 & 2.5 \\
\hline Diabetes mellitus + Liver problem & 4 & 2 \\
\hline Diabetes mellitus + Hypothyroidism & 7 & 3.5 \\
\hline Diabetes + Chronic obstructive pulmonary disease & 1 & 0.5 \\
\hline Diabetes mellitus + Diabetic retinopathy & 3 & 1.5 \\
\hline Diabetes mellitus + Tuberculosis & 3 & 1.5 \\
\hline Diabetes mellitus + Cancer & 1 & 0.5 \\
\hline Diabetes mellitus + Anemia & 1 & 0.5 \\
\hline Diabetes mellitus + Diabetic foot & 2 & 1 \\
\hline Diabetes mellitus + Gastritis & 2 & 1 \\
\hline Diabetes mellitus + Hypertension + Diabetic foot & 1 & 0.5 \\
\hline Diabetes mellitus + Myocardial infarction + Asthma & 2 & 1 \\
\hline Diabetes mellitus + Hypertension + Asthma & 2 & 1 \\
\hline Diabetes mellitus + Hypertension + Congestive heart failure & 1 & 0.5 \\
\hline Total & 117 & \\
\hline
\end{tabular}

*The percentage of the concomitant disease has been calculated from a pool of 200 patients.

\section{Discussion}

This is very first medicine utilization study of OHAs conducted at our university hospital. Type 2 diabetes mellitus was found to be most prevalent (32.5\%) in the age group of $41-50$ years (mean age $50.4 \pm 11.7$ years). The above figures indicate that type 2 diabetes is more prevalent in middle aged people. A study from Spain reported higher mean age, $60.5 \pm 12.8$ years in type 2 diabetes patients [24]. The proportions of male and female patients indicate that type 2 diabetes is slightly more common in case of female patients. This may be assigned to the fact that women are more obese than men [25] [26]. The other reasons might be due to lack of physical activity, life style changes, dietary habit and stress. Weight control would be the most effective way to reduce chances of type 2 diabetes. A high proportion (18\%) of the study population was found to be linked with family history of type 2 diabetes mellitus.

The mean number of OHAs per prescription was found to be 2.2, which is higher than the number reported by Sutharson et al., and lower than the previous records of 2.99 from Hong Kong [27]. In the present study metformin (biguanide) consumption was high (37\%), followed by sulfonylureas (31.9\%). Das et al., reported biguanides (24.5\%) and sulphonylureas (19.9\%) as the most commonly prescribed OHAs [28]. Desai et al., reported the proportion of newly diagnosed patients initially treated with metformin increased from $51 \%$ to $65 \%$, whereas those receiving sulfonylureas decreased from $26 \%$ to $18 \%$ [29]. Boccuzzi et al, reported consumption of sulphonylureas that of $66.4 \%$ and metformin $24.3 \%$ [30]. A study from Taiwan reported sulfonylureas as the most commonly prescribed drug class followed by biguanides [31]. Metformin is the therapy of choice for overweight and obese patients with type 2 diabetes [32]. Metformin acts as a peripheral sensitizer of insulin and also has 
beneficial effects on insulin resistance, an important factor in the pathogenesis of type 2 diabetes. It reduces cardiovascular-related mortality rates more than sulfonylurea [33]. Metformin is unlikely to cause severe hypoglycemia, because it does not stimulate insulin release. So the physicians may have preferred metformin over other OHAs.

A large number of patients (71.5\%) were prescribed combination therapy to control diabetes. Because type 2 diabetes mellitus is a progressive metabolic disease, which is difficult to control, so the physicians may have prescribed more combination medicines to control the blood glucose level in the type 2 diabetes patients. But at the same time it may create problems in forms of drug duplication, chances of drug interaction and adverse drug reactions. A study reported improved glycemic control following the addition of sulfonylureas to metformin, but deterioration resumes as early as 6 months [34]. It is recommended that only WHO approved fixed dose combination products should be prescribed. The use of hospital formulary as approved by a competent pharmacy and therapeutic committee (PTC) is also recommended for rational use of medicines. Furthermore lifestyle modifications, inclusive of dietary modification, regular physical activity and weight reduction are indicated for prevention of type 2 diabetes [35].

Change of dose and frequency was found to be an uncommon practice. Upward dosage change was observed in $6.5 \%$ of the study patients, which is remarkably less than the findings of Baccuzzi et al., who reported $15 \%$ $30 \%$ upward dosage changes [30]. As would be expected, need for dosage titration was justified with increasing duration of therapy, reinforcing issues related to agent efficiency or progression of the disease process. The change in frequency was found to be low, which is a good practice as it helps in patient compliance. As the drug frequency increases, the compliance rate decreases which is supported by previous finding that compliance is better with once daily preparation [36].

Only $77.5 \%$ patients have shown good compliance ( $\geq 80 \%$ intake of recommended dosage regimen) with the prescribed therapy. Patients have shown maximum compliance with biguanides (metformin, $80 \%$ ), followed by sulphonylureas (79.7\%), thiazolidinediones (77.6\%) and least with alpha-glucosidase inhibitors (70.4\%). Donnan et al., reported greater than 90\% compliance in case of sulphonylureas [37]. They reported $39 \%$ compliance in case of metformin which is just half than the present study [37]. Boccuzzi et al., reported $60 \%$ for metformin [30]. Decreased compliance was observed in case of longer duration of diabetes patients. Good compliance to the therapy was found, which can be further improve by patient education, health professional education, use of daily dose regimen, or monitored dosage system, and greater care involvement in medication management [38]. Furthermore, the diabetic patients should be counseled about the chronic nature of the disease, dietary advice and importance of pharmacological as well as non-pharmacological intervention and consequences of non-compliance with the therapy.

Inclination to brand name prescribing (99.3\%) was extremely significant, $\mathrm{p}<0.0001$ than prescribing by generic names $(0.7 \%)$. In a recent Indian study from Allahabad, it was reported that only $2 \%$ of the medicines were prescribed by generic names [39]. Upadhyay et al., reported $47.5 \%$ medicines prescribed by generic name in Nepal [40]. This might be due to the absence of hospital formulary system and biased promotion of selected brands by the medical representatives of pharmaceutical manufacturers, which is a common practice in Indian hospitals. Prescribing by generic names should be promoted, as it could help in cheaper treatment to the patients, reduce chance of drug duplication, drug interactions and adverse drug reactions.

Secondary failure was observed in $7.5 \%$ of the patients in the present study, which is lesser than the findings of Boccuzzi et al. [30]. Compared with sulfonylurea therapy, metformin therapy appears to be associated with a delay in the onset of secondary failure which is corroborated by previous report [41]. The reason of the secondary failure may be non-compliance with the therapy, inappropriate drug selection and lack of timely drug therapy review. As type 2 diabetes mellitus advances, secondary failure of OHAs develops as a consequence of progressive loss of beta-cell function and worsening of insulin resistance caused by persistent hyperglycemia and possible development of drug resistance [42]. Periodic intravenous infusions of insulin are proposed for the treatment of type 2 diabetes mellitus patients that have become resistant to oral therapy [43].

More than half of the study population was found to be co-morbid with various conditions. Hypertension was found to be most commonly associated disease (31\%) with diabetes, which is well corroborated with the findings of Bener et al., who reported 29\% hypertension as co-morbid in case of diabetics [44]. These findings are significantly alarming, as hypertension is a predictor of cardiovascular disease. It is observed that among the study population more than half, $55 \%$ patients had a BMI $\geq 25 \mathrm{~kg} / \mathrm{m}^{2}$. Since, obesity is considered to be a major risk factor for hypertension; it means that patients with diabetes and hypertension are at greater risk of having 
metabolic, cancer and cardiovascular morbidity [45]. Patients having BMI, in between $25-30 \mathrm{~kg} / \mathrm{m}^{2}$ are also at greater risk of having glucose intolerance [25]. Obesity is considered to be the link between insulin resistance and metabolic abnormalities inclusive of diabetes, hypertension and dyslipidemia, all of which are risk factors for coronary artery disease. Limitations of the study included small sample size and short duration of the study.

\section{Conclusion}

Biguanides was the most frequently prescribed OHAs. The result of the present study highlights the need for comprehensive management of diabetic patients, including life-style changes, dietary control, hypoglycemic agents, cardiovascular prevention, treatment of complications and co-morbidity. Most often, clinical effectiveness is influenced by prescribers' agent selection and therapy changes as well as patient adherence with prescribed drug regimens. Clinical monitoring of patient's adherence to the prescribed treatment to achieve good glycemic control is also recommended. Measures should be taken to improve patient adherence to the prescribed treatment for better management of type 2 diabetes mellitus.

\section{Acknowledgements}

The authors appreciate the cooperation of all the physicians, healthcare members of the Majeedia Hospital and the patients who participated in the present study.

\section{References}

[1] Ahmed, A.M. (2002) History of Diabetes Mellitus. Saudi Medical Journal, 23, 373-378.

[2] Olokoba, A.B., Obateru, O.A. and Olokoba, L.B. (2012) Type 2 Diabetes Mellitus: A Review of Current Trends. Oman Medical Journal, 27, 269-273.

[3] Stratton, I.M., Adler, A.I., Neil, H.A., Matthews, D.R., Manley, S.E., Cull, C.A., Hadden, D., Turner, R.C. and Holman, R.R. (2000) Association of Glycemia with Macrovascular and Microvascular Complications of Type 2 Diabetes (UKPDS 35): Prospective Observational Study. British Medical Journal, 321, 405-412. http://dx.doi.org/10.1136/bmj.321.7258.405

[4] Action to Control Cardiovascular Risk in Diabetes Study Group, Gerstein, H.C., Miller, M.E., Byington, R.P., Goff Jr., D.C., Bigger, J.T., Buse, J.B., Cushman, W.C., Genuth, S., Ismail-Beigi, F., Grimm Jr., R.H., Probstfield, J.L., Simons-Morton, D.G. and Friedewald, W.T. (2008) Effects of Intensive Glucose Lowering in Type 2 Diabetes. New England Journal of Medicine, 358, 2545-2549.

[5] Advance Collaborative Group, Patel, A., MacMahon, S., Chalmers, J., Neal, B., Billot, L., Woodward, M., Marre, M., Cooper, M., Glasziou, P., Grobbee, D., et al. (2008) Intensive Blood Glucose Control and Vascular Outcomes in Patients with Type 2 Diabetes. New England Journal of Medicine, 358, 2560-2572. http://dx.doi.org/10.1056/NEJMoa0802987

[6] Raz, I., Wilson, P.W., Strojek, K., Kowalska, I., Bozikov, V., Gitt, A.K., Jermendy, G., Campaigne, B.N., Kerr, L., Milicevic, Z., et al. (2009) Effects of Prandial versus Fasting Glycaemia on Cardiovascular Outcomes in Type 2 Diabetes: The Heart 2D Trial. Diabetes Care, 32, 381-386. http://dx.doi.org/10.2337/dc08-1671

[7] Davis, S.N. and Granner, D.K. (2001) Insulin, Oral Hypoglycemic Agents and the Pharmacology Endocrine Pancreas. In: Hardman, J.G. and Limbird, L.E., Eds., Goodman and Gilman's T Pharmacological Basis of Therapeutics, McGraw Hill, New York, 1526-1531.

[8] Campbell, I.W. and Lebovitz, H. (2000) Fast Facts-Diabetes Mellitus; What Is Type 2 Diabetes? 2nd Edition, Health Press Ltd., Oxford, 18-25.

[9] Cox, E.M. and Elelman, D. (2009) Test for Screening and Diagnosis of Type 2 Diabetes. Clinical Diabetes, 4, 132138.

[10] International Expert Committee (2009) International Expert Committee Report on the Role of the A1C Assay in the Diagnosis of Diabetes. Diabetes Care, 32, 1-8.

[11] Ahmann, A.J. and Riddle, M.C. (2002) Current Oral Agent for Type 2 Diabetes. Postgraduate Medicine, 111, 32-46.

[12] Wild, S., Roglic, G., Green, A., Sicree, R. and King, H. (2004) Global Prevalence of Diabetes: Estimates for the Year 2000 and Projections for 2030. Diabetes Care, 27, 1047-1053. http://dx.doi.org/10.2337/diacare.27.5.1047

[13] King, H., Aubert, R.E. and Herman, W.H. (1998) Global Burden of Diabetes, 1995-2025: Prevalence, Numerical Estimates and Projections. Diabetes Care, 21, 1414-1431.

[14] Pradeep, A.R. and Mohan, V. (2002) Changing Scenario of the Diabetes Epidemic. Implications for India. Indian 
Journal of Medical Research, 116, 121-132.

[15] Pradeep, A.R., Deepa, R. and Mohan, V. (2002) Epidemiology of Diabetes in India-Current Perspectives and Future Projections. Journal of Indian Medical Association, 100, 144-148.

[16] National Institute of Diabetes and Digestive and Kidney Diseases (2005) National Diabetes Statistics Fact Sheet: General Information and National Estimates on Diabetes in the United States. US Department of Health and Human Services. National Institute of Health, Bethesda.

[17] Nathan, D.M., Buse, J.B., Davidson, M.B., Ferrannini, E., Holman, R.R., Sherwin, R., Zinman, B., American Diabetes Association and European Association for Study of Diabetes (2006) Management of Hyperglycemia in Type 2 Diabetes: A Consensus Algorithm for the Initiation and Adjustment of Therapy: A Consensus Statement from the American Diabetes Association and the European Association for the Study of Diabetes. Diabetes Care, 29, 1963-1972. http://dx.doi.org/10.2337/dc06-9912

[18] Brown, A.F., Gregg, E.W., Stevens, M.R., Karter, A.J., Weinberger, M., Safford, M.M., Gary, T.L., Caputo, D.A., Waitzfelder, B. and Kim, C. (2005) Race, Ethnicity, Socioeconomic Position, and Quality of Care for Adults with Diabetes Enrolled in Managed Care: The Translating Research into Action for Diabetes (TRIAD) Study. Diabetes Care, 28, 2864-2870. http://dx.doi.org/10.2337/diacare.28.12.2864

[19] Turner, R.C., Cull, C.A., Frighi, V. and Holman, R.R. (1999) Glycemic Control with Diet, Sulfonylurea, Metformin, or Insulin in Patients with Type 2 Diabetes Mellitus: Progressive Requirement for Multiple Therapies (UKPDS 49): UK Prospective Diabetes Study (UKPDS) Group. Journal of American Medical Association, 281, 2005-2012. http://dx.doi.org/10.1001/jama.281.21.2005

[20] Bakssas, I. and Lunde, P.K.M. (1986) National Drug Policies: The Need for Drug Utilization Studies. Trends in Pharmacological Sciences, 7, 331-334. http://dx.doi.org/10.1016/0165-6147(86)90375-5

[21] Hansen, K.N., Mahata, M.C. and Parthasarthi, G. (2004) A Textbook of Clinical Pharmacy Practice: Essential Concepts and Skills. Orient Blackswan, Chennai, 362-375.

[22] Groop, I.C., Pelkonen, R., Koskimies, S., Bottazzo, G.F. and Doniach, D. (1986) Secondary Failure to Treatment with Oral Antidiabetic Agents in Non-Insulin Dependent Diabetes. Diabetes Care, 9, 129-133. http://dx.doi.org/10.2337/diacare.9.2.129

[23] Cumings, K.M., Kirscht, J.P., Becker, M.H. and Levin, N.W. (1984) Construct Validity of the Free Methods for Measuring Patient Compliance. Health Services Research, 19, 103-116.

[24] de Pablos-Velasco, P.L., Martínez-Martín, F.J., Molero, R., Rodríguez-Perez, F., García-Puente, I. and Caballero, A. (2005) Pattern of Prescription of Hypoglycemic Drugs in Gran Canaria (Canary Islands, Spain) and Estimation of the Prevalence of Diabetes Mellitus. Diabetes and Metabolism, 31, 457-462.

[25] Flier, J.S. and Maratos-Flier, E. (2005) Obesity. In: Kasper, D.L., Braunwald, E., Fauci, A.S., Hauser, S.L., Longo, D.L. and Jameson, J.L., Eds., Harrison's Principles of Internal Medicine, 16th Edition, Vol. 1, Medical Publishing Division, McGraw-Hill, New York, 422-429.

[26] Hu, F.B., Manson, J.E., Stampfer, M.J., Colditz, G., Liu, S., Solomon, C.G. and Willett, W.C. (2001) Diet, Lifestyle, and the Risk of Type 2 Diabetes Mellitus in Women. New England Journal of Medicine, 345, 790-797.

[27] Sutharson, L., Hariharan, R.S. and Vamsadhara, C. (2003) Drug Utilization in Diabetology Outpatient Setting of a Tertiary Hospital. Indian Journal of Pharmacology, 35, 237-240.

[28] Das, P., Das, B.P., Rauniar, G.P., Roy, R.K. and Sharma, S.K. (2011) Drug Utilization Pattern and Effectiveness Analysis in Diabetes Mellitus at a Tertiary Care Centre in Eastern Nepal. Indian Journal of Physiology and Pharmacology, 55, 272-280.

[29] Desai, N.R., Shrank, W.H., Fischer, M.A., Avorn, J., Liberman, J.N., Schneeweiss, S., Pakes, J., Brennan, T.A. and Choudhry, N.K. (2012) Patterns of Medication Initiation in Newly Diagnosed Diabetes Mellitus: Quality and Cost Implications. American Journal of Medicine, 125, 302.e1-7. http://dx.doi.org/10.1016/j.amjmed.2011.07.033

[30] Boccuzzi, S.J., Wogen, J., Fox, J., Sung, J.C., Shah, A.B. and Kim, J. (2001) Utilization of Oral Hypoglycemic Agents in a Drug-Insured US Population. Diabetes Care, 24, 1411-1415.

[31] Chiang, C.W., Chiu, H.F., Chen, C.Y., Wu, H.L. and Yang, C.Y. (2006) Trends in the Use of Oral Antidiabetic Drugs by Outpatients in Taiwan: 1997-2003. Journal of Clinical Pharmacy and Therapeutics, 31, 73-82. http://dx.doi.org/10.1111/j.1365-2710.2006.00705.x

[32] Cusi, K. and Defronzo, R.A. (1998) Metformin: A Review of Its Metabolic Effects. Diabetes Review, 6, 89-131.

[33] Johnson, J.A., Majumdar, S.R., Simpson, S.H. and Toth, E.L. (2002) Decreased Mortality Associated with the Use of Metformin Compared with Sulfonylurea Monotherapy in Type 2 Diabetes. Diabetes Care, 25, 2244-2248.

[34] Cook, M.N., Girman, C.J., Stein, P.P., Alexander, C.M. and Holman, R.R. (2005) Glycemic Control Continues to Deteriorate after Sulfonylureas Are Added to Metformin among Patients with Type 2 Diabetes. Diabetes Care, 28, 9951000. 
[35] Laakso, M. and Letho, S. (1997) Epidemiology of Macrovascular Disease in Diabetes. Diabetes Reviews, 5, $294-315$.

[36] Paes, A.H., Bakker, A. and Soe-Agnie, C.J. (1997) Impact of Dosage Frequency on Patient Compliance. Diabetes Care, 20, 1512-1517. http://dx.doi.org/10.2337/diacare.20.10.1512

[37] Donnan, P.T., MacDonald, T.M. and Morris, A.D. (2002) Adherence to Prescribed Oral Hypoglycemic Medications in a Population of Patients with Type 2 Diabetes: A Retrospective Cohort Study. Diabetic Medicine, 19, 279-284. http://dx.doi.org/10.1046/j.1464-5491.2002.00689.x

[38] Brown, J.B., Nichols, G.A., Glauber, H.S. and Bakst, A. (1999) Ten-Year Follow-Up of Antidiabetic Drug Use, Nonadherence and Mortality in a Defined Population with Type 2 Diabetes Mellitus. Clinical Therapeutics, 21, 1045-1057. http://dx.doi.org/10.1016/S0149-2918(99)80023-X

[39] Ansari, K.U., Singh, S. and Pandey, R.C. (1998) Evaluation of Prescribing Pattern of Doctors for Rational Medicine Therapy. Indian Journal of Pharmacology, 30, 43-46.

[40] Upadhyay, D.K., Palaian, S., Prasad, R.S., Mishra, P. and Sah, A.K. (2007) Prescribing Pattern in Diabetic Outpatients in a Tertiary Care Teaching Hospital in Nepal. Journal of Clinical and Diagnostic Research, 3, 248-255.

[41] Eurich, D.T., Simpson, S.H., Majumdar, S.R. and Johnson, J.A. (2005) Secondary Failure Rates Associated with Metformin and Sulfonylurea Therapy for Type 2 Diabetes. Pharmacotherapy, 25, 810-816. http://dx.doi.org/10.1592/phco.2005.25.6.810

[42] Polonsky, K.S., Sturis, J. and Bell, G.I. (1996) Non-Insulin-Dependent Diabetes Mellitus-A Genetically Programmed Failure of the $\beta$-Cell to Compensate for Insulin Resistance. New England Journal of Medicine, 334, 777-783. http://dx.doi.org/10.1056/NEJM199603213341207

[43] Mirouze, J. and Augustin-Pascalis, I. (1988) Secondary Failure of Oral Antidiabetic and Dietetic Therapy in Non-InsulinDependent Diabetes Mellitus. Remission through Short Sessions of Continuous Intravenous Insulin Infusion. Diabetes Research and Clinical Practice, 4, 41-46. http://dx.doi.org/10.1016/0168-8227(88)90012-5

[44] Bener, A., Zirie, M., Daghash, M.H., Al-Hamaq, A.O.A.A., Daradkeh, G. and Rikabi, A. (2007) Lipids, Lipoprotein (a) Profile and HbA1c among Arabian Type 2 Diabetic Patients. Biomedical Research, 18, 97-102.

[45] Schorr, U., Blaschke, K., Turan, S., Distler, A. and Sharma, A.M. (1998) Relationship between Angiotensinogen, Leptin and Blood Pressure Levels in Young Normotensive Men. Journal of Hypertension, 16, 1475-1480. http://dx.doi.org/10.1097/00004872-199816100-00011 